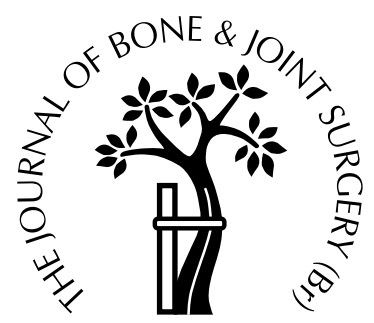

\title{
Accuracy of EBRA-FCA in the measurement of migration of femoral components of total hip replacement
}

\author{
R. Biedermann, M. Krismer, B. Stöckl, P. Mayrhofer, \\ E. Ornstein, H. Franzén \\ From the University of Innsbruck, Austria
}

\begin{abstract}
Geveral methods of measuring the migration of the femoral component after total hip replacement have been described, but they use different reference lines, and have differing accuracies, some unproven. Statistical comparison of different studies is rarely possible.
\end{abstract}

We report a study of the EBRA-FCA method (femoral component analysis using Einzel-Bild-Röntgen-Analyse) to determine its accuracy using three independent assessments, including a direct comparison with the results of roentgen stereophotogrammetric analysis (RSA).

The accuracy of EBRA-FCA was better than $\mathbf{\pm 1 . 5} \mathbf{~ m m}$ (95\% percentile) with a Cronbach's coefficient alpha for interobserver reliability of 0.84 ; a very good result.

The method had a specificity of $100 \%$ and a sensitivity of $78 \%$ compared with RSA for the detection of migration of over $1 \mathrm{~mm}$. This is accurate enough to assess the stability of a prosthesis within a relatively limited period. The best reference line for downward migration is between the greater trochanter and the shoulder of the stem, as confirmed by two experimental analyses and a computer-assisted design.

J Bone Joint Surg [Br] 1999;81-B:266-72.

Received 17 January 1998; Accepted after revision 16 July 1998

R. Biedermann, MD, Registrar

M. Krismer, MD, Associate Professor

B. Stöckl, MD, Senior Registrar

Department of Orthopaedics, University of Innsbruck, Anichstrasse 35, A-6020 Innsbruck, Austria.

P. Mayrhofer, PhD, Assistant Professor

Department of Geometry, Institute of Mathematics and Geometry, University of Innsbruck, Technikerstrasse 113, A-6020 Innsbruck, Austria.

E. Ornstein, MD, Chief Orthopaedic Surgeon

Department of Orthopaedics, Hässleholm-Kristianstad Hospitals, S-281 25

Hässleholm, Sweden.

H. Franzén, MD, PhD, Senior Orthopaedic Surgeon

Department of Orthopaedics, University Hospital of Lund, S-221 85 Lund, Sweden.

Correspondence should be sent to Dr M. Krismer.

(C)1999 British Editorial Society of Bone and Joint Surgery

0301-620X/99/28842\$2.00
Early migration of prosthetic stems and cups is reported to predict later failure, ${ }^{1-3}$ but accurate methods of measurement are needed. Several radiological techniques have been developed, but have different reference lines with varying accuracy. Some authors have measured from the greater trochanter, or a graphic reconstruction based on it, to a second reference point such as the centre of the head, ${ }^{4,5}$ a lateral point on the collar ${ }^{3}$ or the proximal end of the stem. ${ }^{6}$ Others have used reference lines between the lesser trochanter, the lowest margin of the collar, ${ }^{5}$ the distal tip of the stem, ${ }^{7}$ or the centre of the head. ${ }^{8}$ Malchau et al ${ }^{9}$ have compared four different reference lines.

The accuracy of these methods differs. Sutherland et $\mathrm{al}^{5}$ considered that a change in position of the femoral component of over $5 \mathrm{~mm}$ was needed to prove migration, while others using roentgen stereophotogrammetric analysis (RSA) reported an accuracy of about $0.2 \mathrm{~mm}$ for subsidence. ${ }^{10-15}$ Ilchman et al ${ }^{16}$ compared four different radiological methods for migration of the acetabular component with the proven accuracy of RSA. Krismer et $\mathrm{al}^{17}$ compared results from pairs of radiographs taken within one month, assuming that migration was unlikely within such a short period in apparently stable prostheses.

Wetherell, Amis and Heatley, ${ }^{18}$ using radiographs, determined the accuracy of reference lines of three dried pelvic specimens in different positions of rotation and tilt. Krismer et $\mathrm{al}^{19}$ determined the accuracy analysing implausible results such as the upward migration of femoral components or the downward migration of cups. Walker et $\mathrm{al}^{3}$ calculated the maximum error for changes in femoral orientation and confirmed these in an experimental analysis.

The EBRA method (in German: Einzel-Bild-RöntgenAnalyse) of measuring migration has $1 \mathrm{~mm}$ confidence limits for acetabular components, using pairs of conventional comparable radiographs. ${ }^{17}$ The principles of the EBRA method have now been adapted to measure migration of the femoral component from standard radiographs; the method is known as EBRA-FCA (femoral component analysis).

We aimed to identify the most appropriate reference points and lines and to determine the accuracy of EBRAFCA using at least three independent methods. 


\section{Methods}

Data collection and analysis. The EBRA-FCA method can be applied to marked reference points on plain or scanned radiographs. For plain films, we used a digitiser and digitising table linked to an IBM-compatible computer. Data on the radius of the femoral head are used in the graphic program to correct for magnification. The radiographs are marked with reference lines based on an axis through the femoral component from which 19 reference points are entered for the femur and the prosthesis (points 1 to 19 on Fig. 1). The femoral axis is the midline of two tangents drawn between the points A, B, C and D shown in Figure 1 on the outline contour of the shaft.

For measurement of subsidence the most important reference points are shown by black circles in Figure 1 and are: a) the centre of the head, calculated from reference points 1 to 7

b) the intersection of the axis and the shoulder of the prosthesis (reference point 19);

c) the intersection of two defined tangents on the lesser trochanter (reference point 12) (these are drawn in relation to the stem axis, using a choice of angles); and

d) the intersection of the axis and a tangent to the most prominent point of the greater trochanter (reference point 8).
From these points and the distances between them a computer file is created which contains all necessary data for the analysis. The EBRA-FCA program then provides information about subsidence, the medial and lateral distances between the prosthesis and the bone margins, the angle between bone and stem, and the magnification in relation to head size and stem length.

There is a choice of four different reference lines $(a, b, c, d)$ for the measurement of migration as shown in Figure 2.

Comparability of radiographs. The EBRA-FCA method uses three parameters to assess the comparability of pairs of radiographs (Fig. 3), and accepts only pairs within chosen limits. The result for each is then weighted according to the comparability parameters. The final value for all acceptable radiographs in a series is then calculated from the individual results (Fig. 4).

\section{The accuracy of EBRA-FCA}

We evaluated the accuracy of four different reference lines, using three methods, and a computer-assisted design (CAD) simulation.

Pairs of radiographs taken within one month. We assumed that migration of apparently stable stems did not occur in such a short period. We analysed our data for 33 pairs of radiographs of stable implants, and regarded any migration as showing error in measurement.

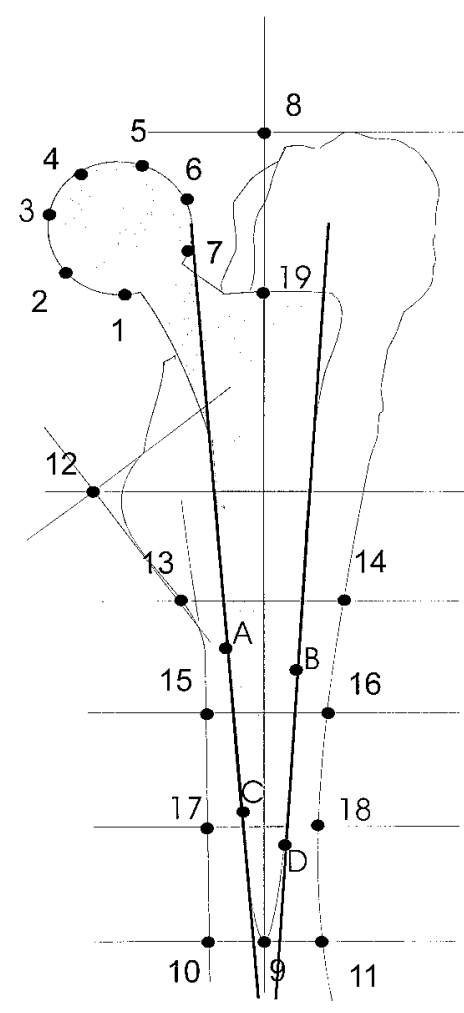

Fig. 1

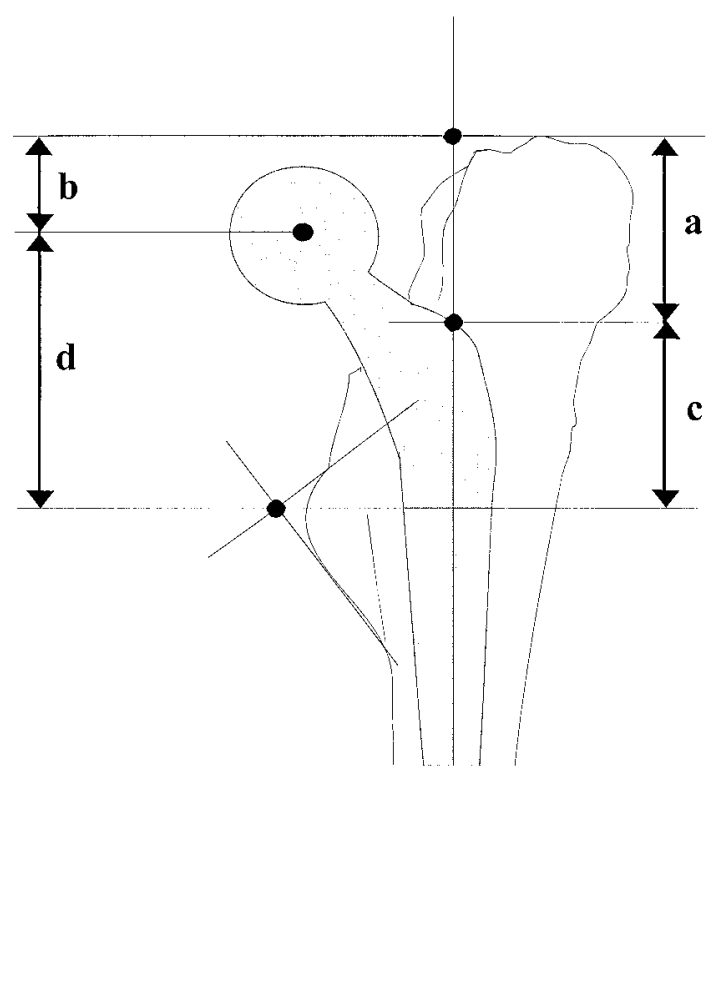

Fig. 2

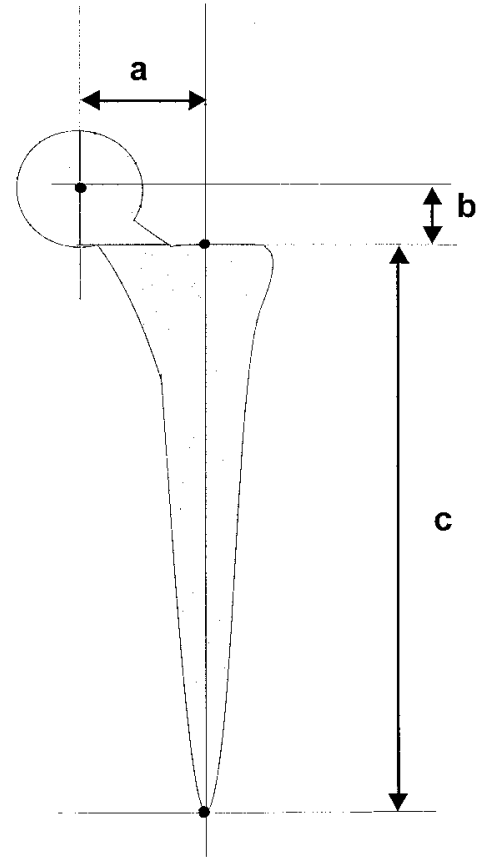

Fig. 3

Figure 1 - Diagram indicating the reference points 1 to 19 and A to D used in the EBRA-FCA program, as explained in the text. Figure 2 - Diagram showing the four reference points used for the measurement of migration marked by black circles. The vertical distances are a) greater trochanter to stem shoulder, b) greater trochanter to centre of prosthetic head, c) lesser trochanter to stem shoulder, and d) lesser trochanter to centre of head. Figure 3 -

Diagram showing the three measurements used to assess comparability between pairs of radiographs. 
R. BIEDERMANN, M. KRISMER, B. STÖCKL, P. MAYRHOFER, E. ORNSTEIN, H. FRANZEN

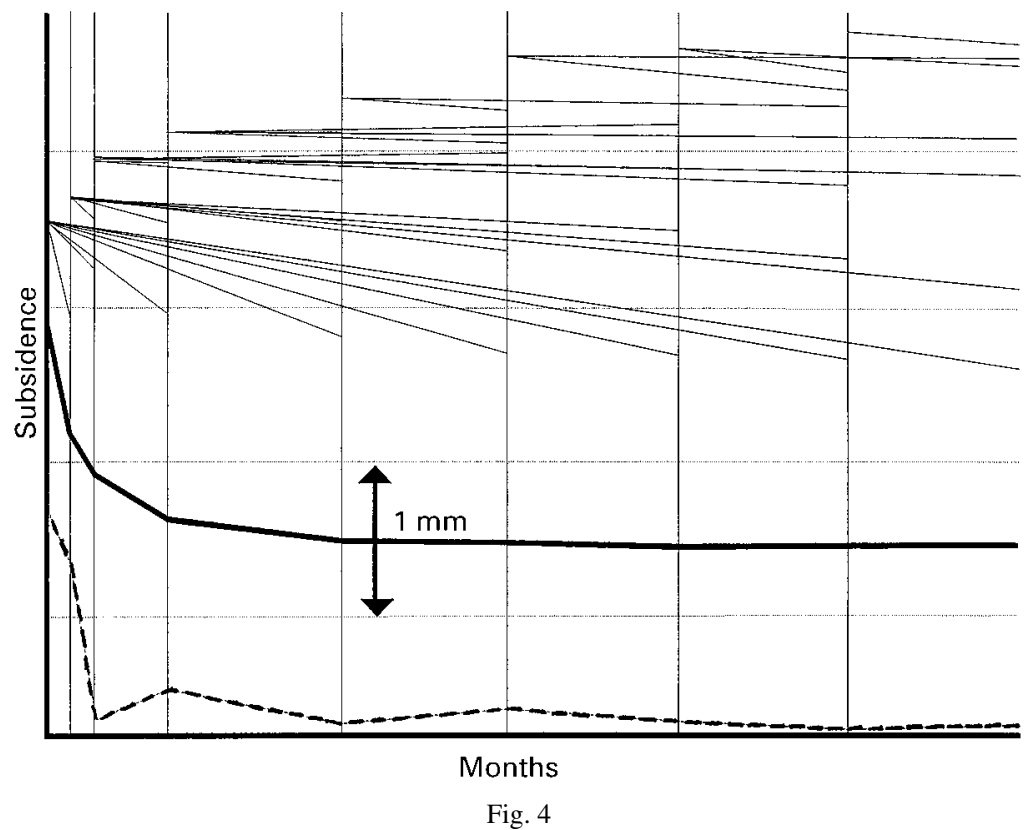

Diagrams of the results of one series, with individual comparisons between pairs in the upper half. The middle bold line is a summary for results from comparable radiographs, and the lower dotted line is the results without ensuring the comparability of radiographs.

Apparent upward migration. We assumed that true upward migration cannot occur and that results which showed this were due to the inaccuracy of the method. We studied 1163 radiographs taken for a separate study of 59 cemented Müller and 58 non-cemented porous-coated anatomic stems with a mean observation period of 96 months, measuring an average of ten radiographs in each individual series. Data were obtained from the EBRA-FCA input program and used to evaluate statistically the value of the four reference lines and the limits of comparability for migration of 2,3 and $4 \mathrm{~mm}$, all in relation to the type of femoral component. We then used ANOVA, with the Tukey test for multiple comparisons, to examine differences between reference lines, limits of comparability and stem type for upward migration, the result which best indicated the inaccuracy of the method. Significance levels were set at 0.05 .

Comparison with RSA. For the third method of assessing accuracy, we studied eight series of RSA compatible radiographs by the EBRA-FCA method, using four observers and limits of comparability of 3 and $4 \mathrm{~mm}$. These results were compared with the RSA data, disregarding any RSA error. Each of the eight series included radiographs taken postoperatively after six weeks and at 3, 6, 12, 18 and 24 months. All data were obtained independently and blinded; they were later put together for statistical analysis. The RSA figures were provided by different observers in another institution. Since pairs of radiographs which were not comparable by the EBRA-FCA program were excluded, $15 \%$ of the EBRA information on migration data for a period of at least 18 months was not available. Therefore partial migration was determined between successive comparable radiographs.
In a second investigation we compared the total migration within the maximum usable observation time of the EBRA-FCA results with the information from RSA over the same periods.

Interobserver variation. The four independent investigators were one trainee and three experienced observers. We compared their migration results for each series at the periods listed above with limits of comparability of 3 and $4 \mathrm{~mm}$, using Cronbach's coefficient alpha to estimate the reliability of the proportion of the observed variance due to true differences among measurements. This assesses the internal consistency between sets of measurements, and values of Cronbach alpha greater than 0.75 indicate good reliability.

CAD simulation. We also studied the errors in measurements of subsidence from standard anteroposterior radiographs of the pelvis or hip due to femoral rotation and flexion by simulating radiological exposures with CAD. We used an Auto CAD 13 system (Autodesk AG, Basel, Switzerland) which allowed the whole model of the femoral component to be rotated longitudinally (internal/external rotation) and about a transverse axis (flexion/extension). The system displayed all different states of rotation simultaneously using a perspective projection to simulate radiography (Fig. 5). We could also use different settings for the central beam and focus-to-film distance for pelvic and hip radiographs.

For this study we did not use the comparability strategy of EBRA since any correction based on similarity of images could only improve the results. It was therefore a worst-case study for from $5^{\circ}$ internal to $20^{\circ}$ external rotation and from $5^{\circ}$ extension to $20^{\circ}$ flexion. 


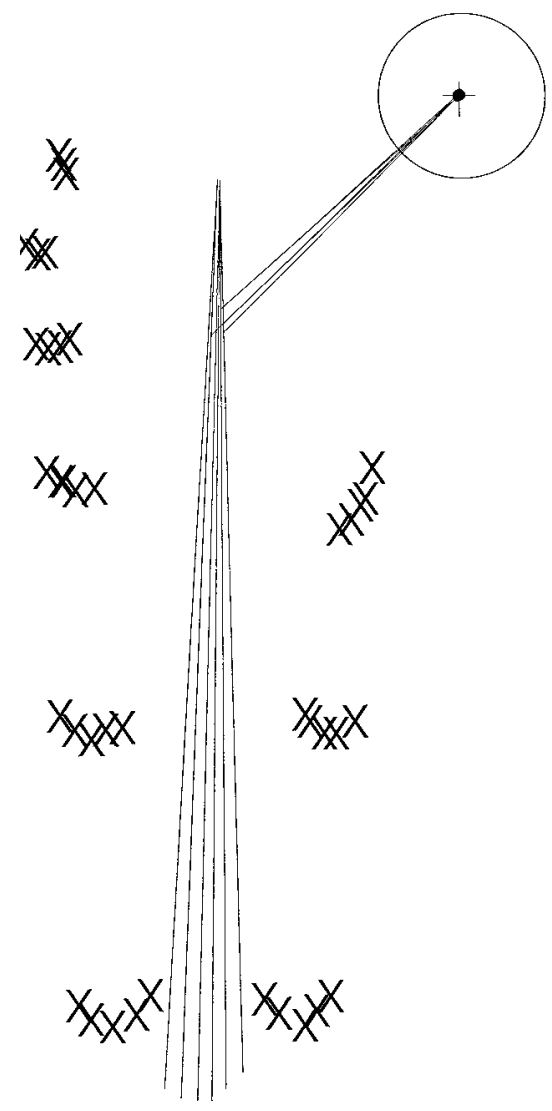

Fig. 5

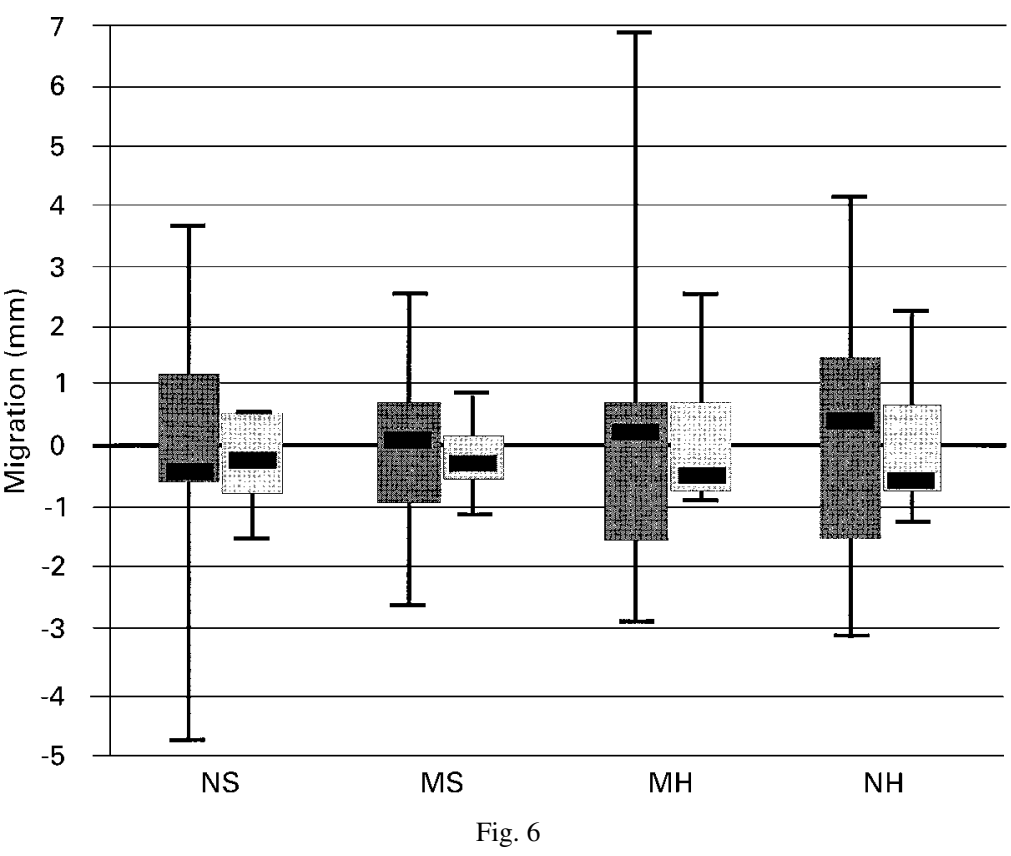

Figure 5 - Diagram to show the influence of CAD-simulated movement of the prosthesis from $20^{\circ}$ flexion to $5^{\circ}$ extension and $5^{\circ}$ internal rotation to $20^{\circ}$ external rotation on some of the reference points, marked by Xs. The top of the greater trochanter shows the smallest change and is therefore the best reference point, as confirmed by Table II. Figure $6-$ Apparent migration in pairs of radiographs of stable prostheses taken within one month using the four different measurements of distance shown in Figure 2. NS, lesser trochanter to stem shoulder; MS, greater trochanter to stem shoulder; $\mathrm{MH}$, greater trochanter to centre of head; $\mathrm{NH}$, lesser trochanter to centre of head. The first, darker, bars show the results from all data in 33 pairs as medians, interquartile ranges and 95\% CLs. The lighter grey bars are the parallel results for the nine pairs with comparable data (see text). The median for MS was 0.01 for the raw data and -0.3 for comparable data.

\section{Results}

\section{The accuracy of EBRA-FCA}

Comparison within one month. For the 33 pairs of radiographs the maximum migration for the best measurement of the greater trochanter to the stem shoulder was $+2.5 \mathrm{~mm}$ and $-2.6 \mathrm{~mm}$ respectively, but only nine (27\%) of the pairs were comparable in the EBRA-FCA graphic program with a comparability limit of $4 \mathrm{~mm}$. For the nine comparable pairs the range was -1.1 to $+0.8 \mathrm{~mm}$ (Fig. 6). For series with more than two radiographs, the number and proportion of comparable pairs will be greater.

Apparent upward migration. Using the best reference distance for migration, from the greater trochanter to stem shoulder, the mean apparent upward migration was $0.24 \mathrm{~mm}$ (Fig. 7).

ANOVA and Tukey testing confirmed that the reference distance between the greater trochanter and stem shoulder gave the best accuracy with $95 \%$ percentiles of $0.9 \mathrm{~mm}$. By contrast, we found no significant difference between the two types of femoral component, or in the use of different limits of comparability.

Comparison with RSA. The maximum and minimum mean differences for all four observers are compared with the RSA data in Figure 8. In the series with a minimum observation of 18 months the $95 \%$ percentiles of differences between EBRA-FCA and RSA were $\pm 1.6 \mathrm{~mm}$ with

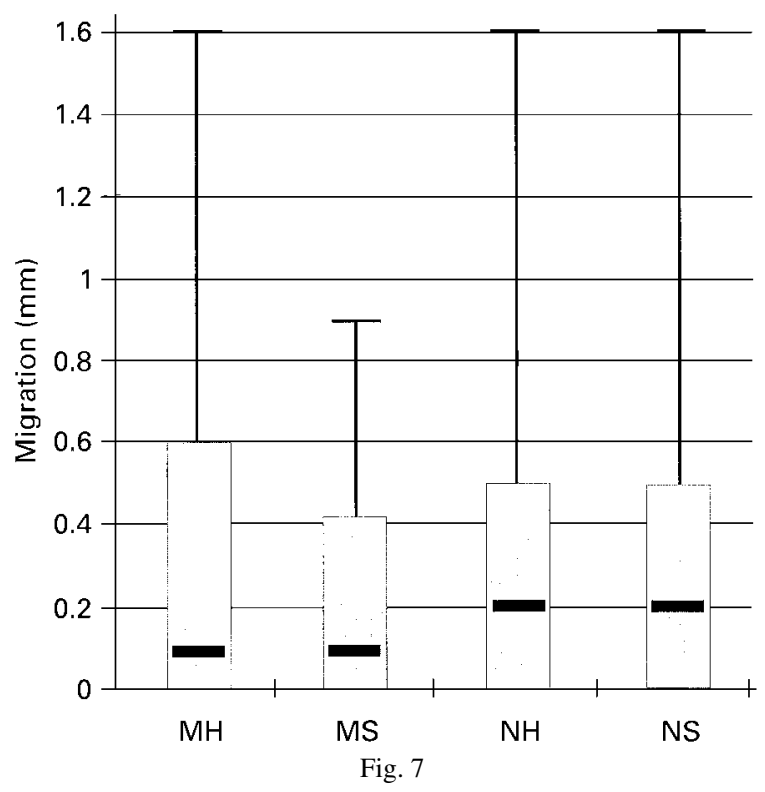

Summary of the results for each of the four reference lines showing apparent upward migration in 996 diagrams as medians, interquartile ranges and $95 \%$ percentiles (Kruskal-Wallis one-way ANOVA, $\mathrm{p}<0.001$ for the difference between MS and all others). Note that the order of reference line is different in Figures 6 and 7.

an interquartile range of +1.0 to $-0.3 \mathrm{~mm}$. The three experienced EBRA-FCA observers had better results with $95 \%$ percentiles between +1.5 and $-1.2 \mathrm{~mm}$ and interquartile 


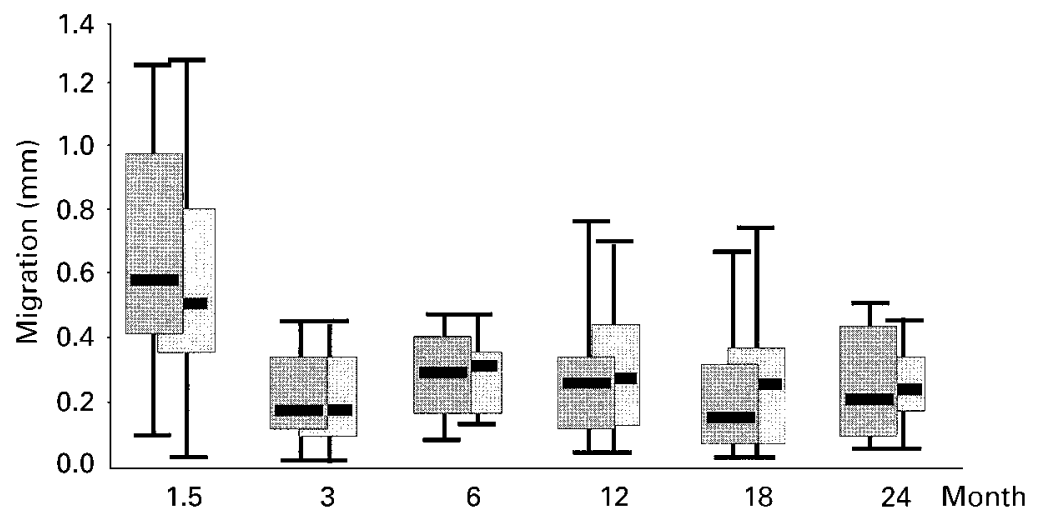

Fig. 8

Differences in migration shown by EBRA-FCA and by RSA for pairs of successive radiographs, calculated using absolute values. The darker grey blocks were from 32 cases using a $3 \mathrm{~mm}$ EBRA limit, and the lighter ones derived from a $4 \mathrm{~mm}$ limit. The median differences, interquartile and $95 \%$ percentile ranges are shown as in Figures 6 and 7.

Fig. 9

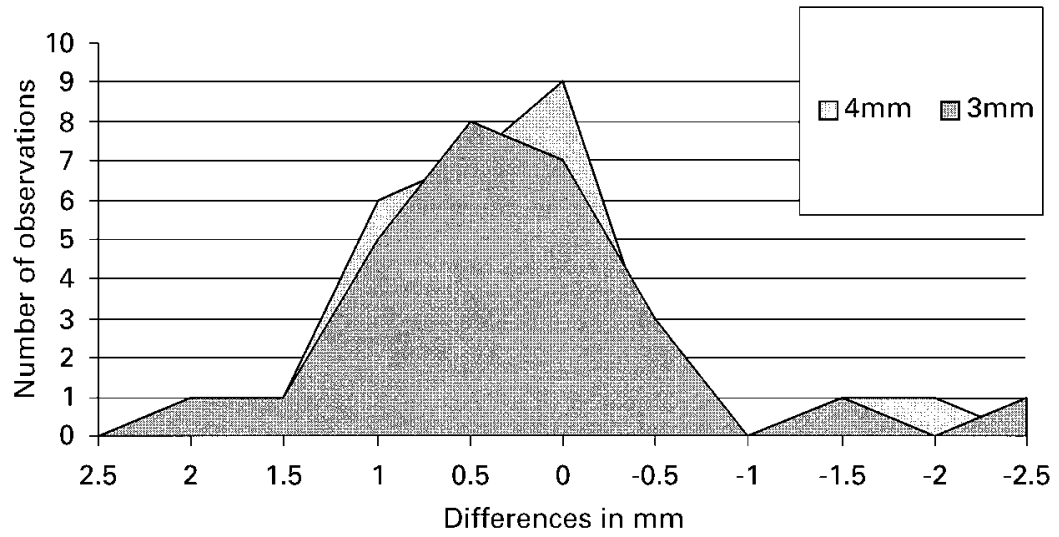

Frequency curve for the differences in measurement of migration between RSA and EBRA-FCA for $3 \mathrm{~mm}$ and $4 \mathrm{~mm}$ comparability limits. Subsidence is the RSA result in mm minus the EBRA-FCA results in $\mathrm{mm}$ $(\mathrm{n}=27$ for each comparability limit)

ranges between +0.9 and $-0.3 \mathrm{~mm}$.

Figure 9 shows that EBRA-FCA tends to underestimate migration, as demonstrated by the mean values, all between +0.45 and $+0.5 \mathrm{~mm}$. All the RSA results showed migration of over $1 \mathrm{~mm}$ (1.4 to 4.3 ; median 2.3). We therefore examined the EBRA-FCA results of all four observers in the detection of migration of over $1 \mathrm{~mm}$, compared with RSA data of the same period. Table I shows that EBRAFCA detected migration of over $1 \mathrm{~mm}$ with a specificity of $100 \%$ and a sensitivity of $78 \%$, giving a positive predictive value of $100 \%$ since all such migration found with EBRA-

Table I. Detection of migration of over $1 \mathrm{~mm}$ by EBRA-FCA compared with RSA data for the same period, showing that the sensitivity of EBRA is $78 \%$ and specificity is $100 \%$

\begin{tabular}{llll}
\hline $\begin{array}{l}\text { EBRA-FCA } \\
\text { migration }\end{array}$ & \multicolumn{2}{l}{ RSA migration } & $\mathbf{>} \mathbf{1 m m}$ \\
\cline { 2 - 4 }$>\mathbf{1 m m}$ & Yes & No & Total \\
\hline Yes & 36 & 0 & 36 \\
No & 10 & 8 & 18 \\
Total & 46 & 8 & 54 \\
\hline
\end{tabular}

Table II. The maximum changes in $\mathrm{mm}$ for the four reference lines in a CAD simulation of $-5^{\circ}$ to $20^{\circ}$ movement in both rotation and flexion/ extension for the AP pelvic and hip radiographs. These are also shown in Figure 5.

\begin{tabular}{lclrl}
\hline Reference point & \multicolumn{2}{c}{ Greater trochanter } & \multicolumn{2}{c}{ Lesser trochanter } \\
\hline Shoulder & 13 & 0.0 & 9.5 & 11.6 \\
Centre of head & 3.3 & 1.4 & 11.8 & 11.3 \\
\hline
\end{tabular}

FCA was shown by RSA.

Interobserver variation. The median differences between observers for absolute values ranged from $0.2 \mathrm{~mm}$ and $0.33 \mathrm{~mm}$, using a $3 \mathrm{~mm}$ limit of comparability. With a limit of $4 \mathrm{~mm}$ the median differences were between 0.21 and $0.34 \mathrm{~mm}$. The $95 \%$ percentiles differed by less than $0.74 \mathrm{~mm}$ for a $3 \mathrm{~mm}$ limit and $0.87 \mathrm{~mm}$ for $4 \mathrm{~mm}$.

The interobserver reliability of results at 24 months was 0.84 with Cronbach's alpha, a very good correlation.

CAD simulation. Table II shows that the best results were for markers at the greater trochanter and the stem shoulder (Fig. 5). The coned hip radiographs gave slightly better results than the pelvic films (Table II).

\section{Discussion}

Reference lines. Wetherell et $\mathrm{al}^{18}$ showed the influence of rotation and tilting on reference lines based on the pelvis, and proposed new measures which would be less affected by the differences in rotation commonly seen in a series of radiographs. For the femoral component, Walker et $\mathrm{al}^{3}$ pointed out that landmarks which are close together on the femur and the stem are best for determining migration. Braud and Freeman, ${ }^{6}$ using a reference line analogous to that for EBRA-FCA showed, by taking radiographs in various positions, that rotation had little effect.

Our CAD experiment clearly indicated that the lesser trochanter was the worst, and that the top of the greater 
trochanter near the shoulder of the prosthesis was the best landmark for the measurement of subsidence. This finding was confirmed with high significance in another two of our independent studies, thus confirming our choice of the reference line between the greater trochanter and the stem shoulder for the measurement of migration by the EBRAFCA method.

Comparability limits. Walker et $\mathrm{al}^{3}$ considered that ranges of up to $10^{\circ}$ of flexion-extension and of internal-external rotation covered possible variations in radiological orientation in long-term follow-up, but we regard this theoretically evaluated angle for flexion-extension as an underestimate.

Malchau et $\mathrm{al}^{9}$ have shown that measurements of stem migration on conventional radiographs varied from $4 \mathrm{~mm}$ up to $10 \mathrm{~mm}$, depending on the choice of landmarks. Our comparison of pairs of radiographs taken within one month showed that this variation is reduced by using only comparable films, as described for the EBRA cup by Ilchmann, ${ }^{20}$ who compared four radiological methods with $\mathrm{RSA}^{16}$ and confirmed that errors were smaller with EBRA than with other standard methods.

Accuracy. Malchau et al $^{9}$ assessed the accuracy of measurements of migration on conventional and digitised radiographs of total hip replacements by comparing the results with RSA. The accuracy (absolute mean $+2 \mathrm{SD}$ ) varied from 3.9 to $12.3 \mathrm{~mm}$ depending on the choice of landmarks, but no correction was made for magnification. Von Müller et $\mathrm{al}^{8}$ claimed an accuracy of $1 \mathrm{~mm}$ for their method, but gave no explanation of their method of calculation. Hardinge et $\mathrm{al}^{7}$ claimed that the Manchester radiograph image-analysis system (MAXIMA) gave reproducibility of measurements of better than $0.01 \mathrm{~mm}$ and an accuracy of $\pm 0.5 \mathrm{~mm}$, but did not investigate or report the accuracy of the method. Braud and Freeman ${ }^{6}$ found that errors in centering of $5 \mathrm{~cm}$ in the X-ray beam produced errors of no more than $0.5 \mathrm{~mm}$, but studied only changes in the same plane.

Walker et $\mathrm{al}^{3}$ calculated the maximum errors due to rotational discrepancy as $0.37 \mathrm{~mm}$ for rotation of $10^{\circ}$ and $0.13 \mathrm{~mm}$ for rotation of $5^{\circ}$. They confirmed these results by an experimental analysis. In an earlier paper Krismer et al $^{17}$ used a similar experimental method to determine the accuracy of the EBRA method, finding a 95\% confidence limit for error of between 0.1 and $0.25 \mathrm{~mm}$, but considered that error to be underestimated by this type of experiment. Another two methods were used to check the results, and both revealed considerably worse accuracy. ${ }^{17}$ To test the accuracy of EBRA-FCA we used three independent analyses. Two showed accuracy better than $1 \mathrm{~mm}$ but the third, a comparison with RSA, was less accurate. We therefore assumed an accuracy of $1.5 \mathrm{~mm}$ for our method.

We found that accuracy decreased with a long observation period, and was better by measurement of partial migration for successive comparable radiographs. The use of comparable radiographs increases accuracy in one respect, but also leads to an underestimate of about $0.5 \mathrm{~mm}$ by smoothing the true migration curve.

Migration, loosening and failure. The rate of migration which is regarded as significant differs considerably; many authors relate this directly to the accuracy of their method.

Sutherland et al, ${ }^{5}$ correcting for magnification, used change in position of the stem of over $5 \mathrm{~mm}$ relative to the bone. Walker et $\mathrm{al}^{3}$ reported migration of less than $2 \mathrm{~mm}$ after two years in $76 \%$ of successful stems, with more than $2 \mathrm{~mm}$ in $84 \%$ of failed stems. Freeman and Plante-Bordeneuve ${ }^{1}$ found a specificity of $86 \%$ and a sensitivity of $78 \%$ for later failure using a threshold migration of $1.2 \mathrm{~mm}$ per year. Kärrholm et al, ${ }^{21}$ studying the Lubinus prosthesis, found that at two years subsidence of more than $1.2 \mathrm{~mm}$ gave a probability of revision of $50 \%$ and of over $2.6 \mathrm{~mm}$ of $95 \%$. The significance of migration rate also varies with the type of femoral component. For one non-coated ribbed model, migration was reported to average $1.06 \mathrm{~mm}$ after two years. ${ }^{22}$ Nistor et $\mathrm{al}^{13}$ found a mean migration of $1.01 \mathrm{~mm}$ after six months, and $2.44 \mathrm{~mm}$ after three years.

We consider that EBRA-FCA has a specificity of $100 \%$ to detect real migration of more than $1 \mathrm{~mm}$. It is accurate enough to assess the stability of prostheses within a relatively limited period and to detect migration of prognostic significance.

The most accurate measurement for the migration of femoral components is between the greater trochanter and the shoulder of the stem. Three different analyses show that the accuracy of EBRA-FCA is -1.1 to $+0.8 \mathrm{~mm}$ for the maximum range, with a $95 \%$ percentile of +1.5 to $-1.2 \mathrm{~mm}$. An accuracy of better than $+1.5 \mathrm{~mm}$ can therefore be assumed. Migration of over $1 \mathrm{~mm}$ can be found by EBRAFCA with a specificity of $100 \%$ and a sensitivity of $78 \%$.

No benefits in any form have been received or will be received from a commercial party related directly or indirectly to the subject of this article.

\section{References}

1. Freeman MAR, Plante-Bordeneuve P. Early migration and late aseptic failure of proximal femoral prostheses. J Bone Joint Surg [Br] 1994;76-B:432-8.

2. Krismer M, Stöckl B, Fischer M, et al. Early migration predicts late aseptic failure of hip sockets. J Bone Joint Surg [Br] 1996;78-B: 422-6.

3. Walker PS, Mai SF, Cobb AG, Bentley G, Hua J. Prediction of clinical outcome of THR from migration measurements on standard radiographs: a study of cemented Charnley and Stanmore femoral stems. J Bone Joint Surg [Br] 1995;77-B:705-14.

4. Schmitz B, Menke W, Michiels I, Fritz M. 5-10 year results with the straight-shaft Müller prosthesis. Z Orthop Ihre Grenzgeb 1994; 132:179-85.

5. Sutherland CJ, Wilde AH, Borden LS, Marks KE. A ten-year follow-up of one hundred consecutive Müller curved-stem total hipreplacement arthroplasties. J Bone Joint Surg [Am] 1982;64-A: 970-82.

6. Braud P, Freeman MAR. The effect of retention of the femoral neck and of cement upon the stability of a proximal femoral prosthesis. J Arthroplasty 1990;5:s5-10.

7. Hardinge K, Porter ML, Jones PR, Hukins DWL, Taylor CJ. Measurement of total hip prostheses using image analysis: the MAXIMA hip technique. J Bone Joint Surg [Br] 1991;73-B:724-8. 
8. Von Müller R, Matuschek T, Thümler P. Digitale Röntgenbildbearbeitung zur Messung von Schaftwaderungen in der Hüftendoprothetik. Orthop Praxis 1996;32:177-9.

9. Malchau H, Kärrholm J, Wang YX, Herberts P. Accuracy of migration analysis in hip arthroplasty: digitized and conventional radiography, compared to radiostereometry in 51 patients. Acta Orthop Scand 1995;66:418-24.

10. Selvik G. Roentgen stereophotogrammetry: a method for the study of the kinematics of the skeletal system. Acta Orthop Scand 1989;60 Suppl 232:1-51.

11. Søballe K, Toksvig-Larsen S, Gelineck $\mathbf{J}$, et al. Migration of hydroxyapatite coated femoral stems: a roentgen stereophotogrammetric study. J Bone Joint Surg [Br] 1993;75-B:681-7.

12. Mjöberg B, Selvik G, Hansson LI, Rosenqvist R, Önnerfält $R$. Mechanical loosening of total hip prostheses: a radiographic and roentgen stereophotogrammetric study. J Bone Joint Surg [Br] 1986; 68-B:770-4.

13. Nistor L, Blaha JD, Kjellström U, Selvik G. In vivo measurements of relative motion between an uncemented femoral total hip component and the femur by roentgen stereophotogrammetric analysis. Clin Orthop 1991;269:220-7.

14. Franzén H, Mjöberg B, Önnerfält R. Early loosening of femoral components after cemented revision: a roentgen stereophotogrammetric study. J Bone Joint Surg [Br] 1992;74-B:721-4.
15. Wykman A, Lundberg A. Subsidence of porous coated non-cemented femoral components in total hip arthroplasty: a roentgen stereophotogrammetric analysis. J Arthroplasty 1992;197-200.

16. Ilchmann T, Franzen H, Mjöberg B, Wingstrand H. Measurement accuracy in acetabular cup migration: a comparison of four radiologic methods versus roentgen stereophotogrammetric analysis. J Arthroplasty 1992;7:121-7.

17. Krismer M, Bauer R, Tschupik J, Mayrhofer P. EBRA: a method to measure migration of acetabular components. J Biomech 1995;28: 1225-36.

18. Wetherell RG, Amis AA, Heatley FW. Measurement of acetabular erosion: the effect of pelvic rotation on common landmarks. $J$ Bone Joint Surg [Br] 1989;71-B:447-51.

19. Krismer M, Tschupik JP, Bauer R, et al. Single-image roentgen analysis for the measurement of hip endoprosthesis migration. Orthopäde 1997;26:229-36.

20. Ilchmann T. Radiographic assessment of cup migration and wear after hip replacement. Acta Orthop Scand 1997;276:1-26.

21. Kärrholm J, Borssén B, Löwenhielm G, Snorrason F. Does early micromotions of femoral stem prostheses matter? 4-7-year stereoradiographic follow-up of 84 cemented hip prostheses. J Bone Joint Surg [Br] 1994;76-B:912-7.

22. Kärrholm J, Snorrason F. Subsidence, tip, and hump micromovements of noncoated ribbed femoral prostheses. Clin Orthop 1993; 287:50-60. 